\title{
A Message from BHAC Board President Combatting Languishing Through Joy and New BHAC Accreditation
}

In our last publication, I spoke of languishing - an emotional state which is neither depression nor thriving, but rather feelings of being stuck, overwhelmed, disengaged, and joyless. These feelings are not abnormal considering we are two years into the COVID-19 pandemic, which dramatically changed our everyday routines. With cases of the delta variant declining and vaccine authorization for children ages 5 to 11 , there is reason to be optimistic about the future. However, adverse ripple effects, including staff shortages, inflation, and global supply chain disruptions still weigh heavy on our communities.

When we are stuck in a languishing state for too long, it can progress into problematic mental health issues, including anxiety, depression, or suicidal ideation and action in extreme instances. Therefore, it is so important to promote and demonstrate taking good self-care to our students, faculty, and staff. In fact, those who have taken good self-care and felt supported in doing so during the pandemic are coping better mentally than those who have not.

What practicing good self-care means to you may be different to someone else, but in a general sense, it's the actions you take to maintain optimal physical and mental health. This includes a wide range of activities from exercising 150 minutes a week, eating 5 veggies/fruits a day, and obtaining $\geq 7$ hours of sleep per night to taking time off from school or work, practicing daily gratitude, or being intentional with making joy a habit. Joy is an excellent antidote to languishing as it provides and restores purpose in living. Joy comes from internal factors and involves what holds ultimate purpose in our lives.

COVID-19 has brought numerous barriers to experiencing joy. For example, because the pandemic has taken place over many months, we have all experienced a collective trauma which may have left some of us in an anxious state. Due to pandemic restrictions, we may have found that what we used to enjoy doing or prioritizing no longer works for us anymore. And lastly, being joyful can feel like a betrayal to those we have lost to COVID-19.

Like anything, joy is a skill, and to bring it back into our lives, we must work to make it a habit. This requires mindfulness and awareness of what brings us a sense of purpose in the current moment. We must allow ourselves space to dream big again and re-evaluate life priorities, values, and beliefs. Start small by jotting a few things down that brought you joy over the past week and explore those options further. Remember, starting a new habit takes time, so be sure to practice self-compassion.

It is now more important than ever for academic institutions to focus on enhancing population health and well-being, especially in the area of mental health and building coping/resiliency skills in faculty, staff, and students as well as creating and sustaining strong wellness cultures. Wellness cannot be an option; it has to be integrated into course work for students, the workday for faculty and staff, and the DNA of the institution. There is so much research that demonstrates the positive associations among wellness, academic performance, and productivity. In order to recognize universities across the country who have achieved excellence in wellness and outcomes, BHAC is launching a new wellness accreditation this spring. The tool for this accreditation is in the beta-testing phase now with a few universities, so please stay tuned for more exciting news about the accreditation process. I hope to see many institutions embrace the process in the near future as it also will serve as a helpful guide in building the healthiest universities. 
I wish all of you a blessed holiday season and New Year. Remember to take a dose of Vitamin G for gratitude every day. I am grateful for our terrific BHAC board, for each of you, and for the terrific collaborative work we do to improve population health and well-being in universities throughout the country.

Best wishes and stay well!

Fond regards,

Bernadette Mazurek Melnyk, PhD, APRN-CNP, FAAN

President and Founder, the National consortium for BHAC

Vice President for Health Promotion

University Chief Wellness Officer

Dean and Helene Fuld Health Trust Professor of Evidence-based Practice, College of Nursing

Professor of Pediatrics and Psychiatry, College of Medicine

Executive Director the Helene Fuld Health Trust National Institute for Evidence-based Practice

The Ohio State University 